\title{
'LOLI-POP' IN AUCKLAND: \\ ENGAGING ASIAN COMMUNITIES AND AUDIENCES THROUGH THE MUSEUM
}

\author{
Bevan K. Y. Chuang and Kathryn A. Hardy Bernal
}

\begin{abstract}
This paper discusses how museums and galleries might positively engage with Asian audiences and bring Asian communities into the museum environment. Museums are cultural institutions that should reflect, preserve, interpret and promote cultural heritage and communities. In the local Acts of the four major metropolitan museums in New Zealand, there are specific requirements for these institutions to represent their communities' ethnic diversities. New Zealand has become increasingly multicultural. According to New Zealand's 2006 census, 17.8 percent of New Zealanders are of non-Pakeha, non-Maori ethnicity, and 22.9 percent were born outside New Zealand. With the growing number of Asians living in New Zealand, and in particular Auckland, a question may be raised as to whether local museums truly reflect and engage with these communities. Using the example of the exhibition Loli-Pop: A downtown Auckland view on Japanese street fashion as a case study (Auckland War Memorial Museum, 14 September - 26 November 2007), the authors explore how New Zealand museums and galleries can effectively reflect and communicate with Asian audiences through exhibition.
\end{abstract}

\section{INTRODUCTION}

Museums are cultural institutions that should reflect, 'preserve, interpret and promote' cultural heritage and communities (ICOM 2006:1). With the growing number of Asians living in New Zealand, and in particular Auckland, it may be asked whether local museums truly engage with this sector of the population.

On 14 September 2007 Loli-Pop: A downtown Auckland view on Japanese street fashion opened at Auckland War Memorial Museum. This exhibition was designed to develop communication with local Asian communities, assist the 
professional development of staff with specialist interests in Asian cultural studies, and enhance public understanding of and relations with Asian cultures.

\section{BACKGROUND}

The racial demographics of New Zealand have changed dramatically over the last decade. Aotearoa New Zealand, considered to be a bicultural nation, needs to re-examine its cultural makeup and determine how it may fit into a more multicultural model, particularly in relation to policies and social services.

Museums in New Zealand and globally are under pressure to be more culturally relevant to multicultural populations (Ang 2005:306). They face strategic issues of both engagement with diverse cultural communities and increasing audience numbers.

According to the 2006 Census (Statistics New Zealand 2006), 18.9 percent of Aucklanders are of Asian descent, ${ }^{1}$ compared with 56.5 percent of European background, 14.4 percent Pacific Peoples, and 11.1 percent Maori. Over 40.4 percent were born overseas. The 2006 Census identified that 31 percent of Asian Aucklanders were of the fifteen to twenty-nine years age bracket and, according to the Asia New Zealand Foundation (2008), the Asian population in New Zealand will continue to be young. This is influenced by the high proportion of Asian international students (87 percent), which is regulated by age through selective immigration criteria (Friesen 2008:16).

It is projected that by $2026 \mathrm{New}$ Zealand's Asian population will continue to rise by 3.4 percent per year. This will be the highest growth rate amongst all ethnic groups (Statistics New Zealand 2008).

\section{MUSEUMS AND THEIR ENGAGEMENT WITH ETHNIC MINORITIES}

'Museums matter only to the extent that they are perceived to provide the communities they serve with something of value beyond their own mere existence' (Weil 2002:4-5). Museums have an important role in the creation and reinforcement of identity (Nishime 2004/2005:44). They also have the ability to teach the wider world about national identities and how to facilitate positive cultural and interfaith understanding. Awareness of cultural identities facilitates individuals to be in tune with the background and attributes of audiences, thus increasing an audience's participation and experience (Yoshitomi 2002: 5). 
An understanding of the significance of cultural diversity within the museum industry is not always very high (Wajid 2008; Steel 2006). Some museum administrators do not believe this to be an important factor and some do not involve their communities in initiatives (Denniston 2003:6). If museums and galleries desire to reflect current national identities, they require policies to embrace diversity by shifting their terrain (Nishime 2004/2005:42).

Internationally, there has been a recent emphasis on ensuring the inclusion of ethnic minorities (or non-Europeans, in Western countries) in the employment of museological professions (Steel 2006). With the assistance of staff from ethnic minority groups, organisations are committed to ensure their relevance and engagement with their constituent populations, particularly in terms of strategic planning and programming (Stephens 2006:13). Ethnic minority staffing allows institutions to learn about stories hidden behind objects, and creates a positive impact on the interpretation of collections, ensuring appropriate representation and display (Porter 2004:23).

An ethnically diverse workforce will guarantee that institutions are able to plan for long-term strategic goals that focus on the attraction of multiple audiences in a way that is culturally appropriate (Heywood 2006: 6; Lavine and Karp 1991:1-9; Steel 2006:11; Stephens 2006:13; Wajid 2008:16; and Shaw 2004:2). Museum and gallery staff still struggle to invent ways to accommodate alternative ethnic viewpoints, as curators continue to impose their own perspectives onto interpretation (Lavine and Karp 1991:4).

By employing an ethnically diverse workforce, museums are able to create an appropriate, engaging, immersive and unforgettable experience for their audiences (Stephens 2006; Steel 2006). The initial experience of museum audiences impacts on whether they decide to return (Yoshitomi 2002: 25). Museum visitors, through word-of-mouth, also greatly influence the reputation of an institution (Porter 2004:13-14).

Museums are often visited for social reasons. Visitors may attend with their families, friends, and guests (Weil 2002:67). The inclusion of ethnic minority staff can enhance the diversity of audiences and increase visitation where staff members will take in their own communities, via friends and family. Such visitors might independently return if their experiences at the museum were immersive and intensive, and had made a positive contribution to their lives (Weil 2002:73-74). 
According to the legislation, the four main metropolitan museums in New Zealand are obliged to connect and engage with their communities. ${ }^{2}$ Most museums in New Zealand do this by developing public programmes and exhibitions that communicate with their local populations.

As an example, in 2007, the Canterbury Museum, in conjunction with the Office of Ethnic Affairs, hosted the Around the World in 30 Lounges exhibition, by working with and exploring the culture of thirty different ethnic groups in the Canterbury region. The Auckland War Memorial Museum, in a similar fashion, and in conjunction with the Asia New Zealand Foundation, hosted the building of Ravanna for the Diwali festival.

These types of programmes, however, are usually carried out by a 'tick-the-box' manner where one ethnic community is 'engaged' and 'consulted' every year.

\section{THE AUCKLAND WAR MEMORIAL MUSEUM}

Auckland War Memorial Museum is situated at the Auckland Domain (Pukekawa), Auckland, New Zealand. The current building has occupied the site since 1929, with subscriptions raised by Auckland people in remembrance of its war dead. The Museum was built by and for Aucklanders. The Museum site is stunning, but not easily accessible. Visitors to the Auckland Museum need to make a conscious decision to attend. This impacts on the types of audiences, as the majority of visitors will attend for a set purpose. This emphasises the need to bring in a more diverse audience that includes minority groups in Auckland, such as the Asian population.

THE MUSEUM'S ENGAGEMENT WITH ASIAN NEW ZEALANDERS

In August 2007, the Museum had only twelve staff members plus twenty-one volunteers of Asian descent in employment. None of these employees represented the Museum at middle or senior management levels. In this situation, Asian employees do not often have opportunities to become involved in decision-making, and may only concentrate on shorter-term projects; in turn, the institution usually relies on these staff members to support smaller schemes to attract audiences outside the usual demographic (Wajid 2008:16).

Indeed, around the Western world, ethnic minority museum staff members are more generally employed in low-status or administrative occupations (Denniston 2003:9-10). ${ }^{3}$ The following examines a case study where Bevan Chuang, an Asian staff member in a lower-ranking administration position 
at Auckland Museum, was allowed the opportunity to manage a temporary exhibition, in collaboration with Kathryn Hardy Bernal, a guest curator from AUT University.

LOLI-POP - THE RATIONALE

A word is enough to the wise ${ }^{4}$

In September 2007 Auckland War Memorial Museum opened two relocated, renewed and improved, permanent galleries, Ancient Civilisation and Arts of Asia. These galleries feature an outstanding selection of objects that span the diverse cultures, histories and civilisations of Asia. They also signify and validate the importance of Asian communities to the Museum and Auckland.

It was perceived that these galleries would appeal to a more mature audience, and given the young population of Asian Aucklanders, it might be difficult to attract a large Asian audience to the Museum, or indeed a young adult interest altogether, via these draw-cards. It was also felt that young Asians should be targeted as a general audience because it was observed that the older generations of Asian communities are more likely to visit museums through the younger members.

An answer as to how a young Asian audience might be enticed into the Auckland Museum came with the Loli-Pop exhibition, designed to coincide with and complement the opening of the new permanent gallery spaces.

LOLI-POP - THE EXHIBITION

\section{Nothing ventured, nothing gained}

Auckland Museum's Loli-Pop exhibition was an exploration into the phenomenon known as the Japanese Gothic and Lolita subculture, its relationship with popular culture (thus 'Lolita' + 'Pop'), and influence on Auckland youth, specifically from the point of view of 'Lolita' fashion design. The so-called Lolita, ${ }^{5}$ the most prominent members of the movement, are signified by their doll-like appearances, inspired by Rococo and frilly Victorian fashions (Figure 1). Some Lolita styles lean more towards the 'Gothic', while others are 'sweeter'. However, there is an overarching emphasis on childlike dress.

Although the Lolita craze has only recently begun to gain ground outside Japan, the phenomenon is not new to the Japanese. 'Ideas that have contributed to the 
style have been around since the seventies, and have evolved from movements such as Glam, Post-Punk, Neo-Romanticism and Goth' (Hardy Bernal 2007). The subculture began to take hold in the 1990s, 'a time when Japan began to

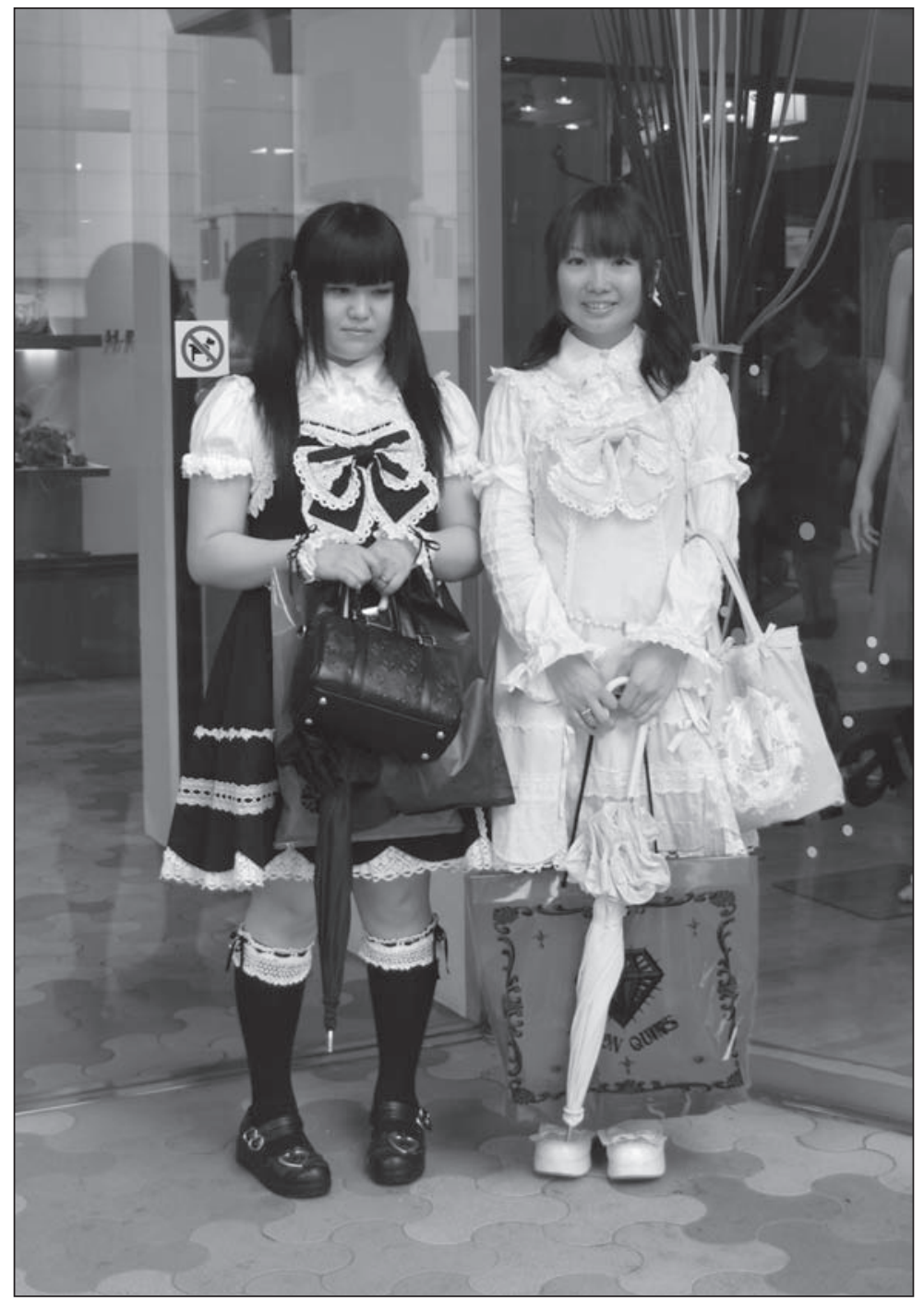

Figure 1: Megumi and Momoko outside Laforet shopping mall, Harajuku, Tokyo, 7 July 2007. Photograph Bevan Chuang. 
face a future fraught with economic instability' (Hardy Bernal 2007). This condition played into the impulse for young women to dress as very young girls, a practice demonstrating a fear of moving into the uncertain realm of adult responsibility, reflecting 'a subconscious desire to hang onto childhood security' (Hardy Bernal 2007). Tiffany Godoy confirms this reading: 'what came out of all of [her] interviews [of Lolita in Japan] was that the [Gothic and Lolita] scene was a reaction to the economy [and that] the idea of growing up was... kind of scary and [so this] was a way to not deal with that' (Mudie 2008:137). Godoy explains that 'there was no longer guaranteed employment, no longer lifetime jobs, so... kids were all of a sudden in a society where nothing was certain anymore' (Mudie 2008:137).

Despite these concerns the Lolita movement is often regarded as superficial by critics who dismiss it 'as infantile behaviour and merely another example of Japan's obsession with all things cute, or kawaii' (Kageyama 2006). ${ }^{6}$ Indeed, the desire to become a member of the Lolita cult is driven by many followers who admire the cuter aspects of the style.

While there can be a sexual connotation associated with the term 'Lolita,' it is the opposing element of childhood innocence, represented by the 'cute', that attracts many participants of the Gothic and Lolita subculture. As Ella Mudie (2008:137) notes, 'looks resembling Western styles don't necessarily carry the same association in Japan'. Godoy further explains that 'if a Japanese girl wears one of those [Goth-Loli] outfits it doesn't look sexy but if a Western girl wears [one it can be considered]... erotic' (Mudie 2008:137). Godoy argues that the look is perhaps only thought to be sexy from a Western perspective, due to 'fixed images that we associate with certain types of [dress, such as]... a doll's outfit, but once you recontextualise it then it takes on a different meaning' (Mudie 2008:137). This opinion has been supported by Makoto Sekikawa, the founding editor of Japan's CUTiE magazine, who has maintained that the kawaii clothing trend, 'as the antithesis of traditional fashion, $[i s]$... not pleasing to the eye of most men' (Mudie 2008:137). However, it is 'precisely this aspect... that $[i s] \ldots$ so appealing' to young women (Mudie 2008:137, citing Sekikawa), and especially to members of the Lolita movement. 'There $[i s] \ldots$ a rebelliousness in it (Mudie 2008:137, citing Sekikawa)' and a rejection of the sexual stereotype.

Western fans profess similar motivations for their attraction towards the Japanese Lolita style. During a research trip to Tokyo in 2007, the curators of LoliPop met Japanese-Californian student Lauren (Figure 2), aged sixteen, who in an interview on the streets of Harajuku, said that what she liked best about the 
fashion was that she could dress in a rebellious way while still being cute and pretty. She felt 'feminine, like a girl, modest, and not too scantily clad'. Like her colleague Erika (Figure 2), seventeen, from Boston, her interest initially came from the music. The genre that many followers of the Gothic and Lolita movement support, called Visual-Kei ('visual style'), is represented by Japanese Rock (J-Rock) groups whose members are known for their heavily made-up and theatrical appearances. A favourite is the now-defunct Malice Mizer (marisu miseru, 1992-2001), a band that through its legendary guitarist Mana, was instrumental in inspiring the look of the Lolita, as well as promoting this style of music. ${ }^{8}$ However, Erika's attraction to Gothic and Lolita differed from her

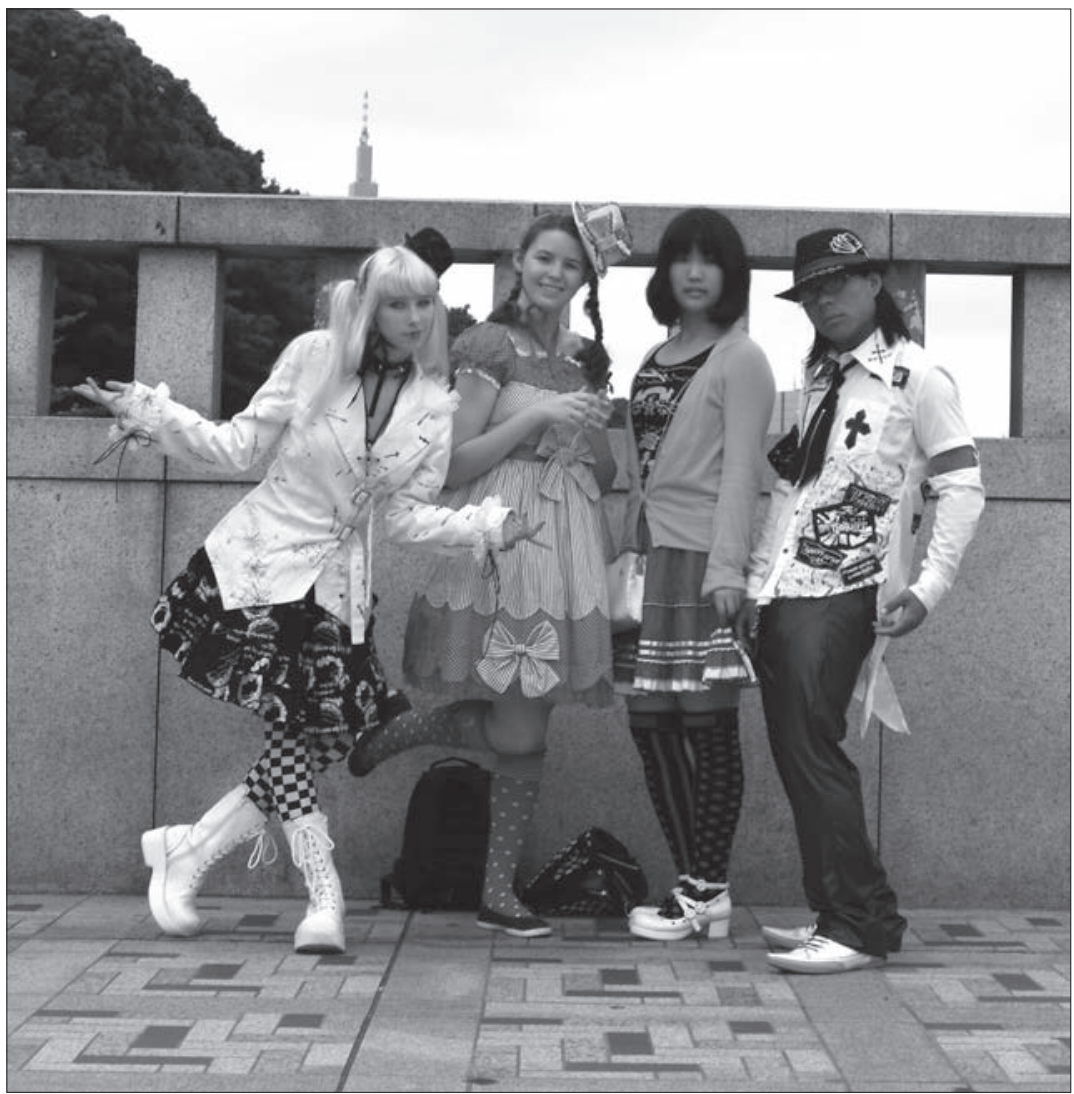

Figure 2: Erika Rogers, Maggie Thorpe, Lauren Ashizawa, and Carlos, on the Jingu-bashi, Harajuku Station Bridge, at the entrance to the Meiji-Jingu Shrine, Tokyo, 8 July 2007. Photograph Bevan Chuang. 
friend's, as she also appreciated the mix between the Victorian influence and contemporary Goth.

Although reasons for taking on the Lolita style vary, Lolita participants, Japanese or otherwise, usually dismiss the Nabokovian undertones that may seem apparent in the subculture's terminology. Members often profess an intention of modesty in their choice to adopt the childlike dress, behaviour and play of the Japanese Lolita, which often includes the collection of dolls.

The Loli-Pop exhibition looked particularly at the strong relationships between the Japanese Lolita and the doll. It highlighted this connection by bringing together a collection of twelve Japanese Lolita-style dolls; ${ }^{9}$ five full-sized Lolita-inspired garments, designed and constructed by AUT University Fashion Department staff members, Angie Finn, Lize Niemczyk, Yvonne Stewart, Gabriella Trussardi, Carmel Donnelly and Kathryn Hardy Bernal; and a backdrop of photographs that illustrated the impact of these outfits when worn, modelled by AUT Bachelor of Design (Fashion) students, Emily Huang, Emily Wang, Shangshang Cookie Wang, Shiahug-Wen Sean Kuo and Yanling Wang. ${ }^{10}$ The context was provided by a visual framework of a further photographic series, comprising shots taken on the streets of Tokyo during the curators' research trip to document current incarnations of the Lolita style (Figure 3); a DVD of footage taken by Bevan Chuang in Harajuku; as well as images of Auckland Lolita (Figure 4), which contributed to the New Zealand perspective. This content was further supported by wall text panels that gave extensive information on the topic, including the origins and history of the Gothic and Lolita movement, its relationship with popular culture, and influences in Auckland. It was considered that this subject matter would resonate not only with a young Asian audience but also with youth in general.

This exhibition also elicited another perspective regarding Japanese subject matter. Within the context of museum display, cultural objects from Asia are often valued more for their significance to their civilisations, than for artistic excellence (Ang 2005:315). While the story surrounding the exhibition was 'anthropological', and intended to enhance education in terms of contemporary Japanese culture and specifically Lolita design, the exhibition was presented as a boutique gallery show in the hanging of the photographic series, but with the dolls and dresses encased in museum cabinets, elevating their preciousness and status, which allowed visitors to view the objects, the exquisite garments, Japanese dolls and photographs, as both valuable and artistic display. ${ }^{11}$ 
THE INFLUENCE OF JAPANESE POPULAR CULTURE

One picture is worth ten thousand words

The Lolita subculture, which is strongly linked with Japanese popular culture, was chosen as a topic because of the growing influence of Japanese culture on contemporary youth worldwide, and a fascination with so-called 'Harajuku girls' (a term made familiar by American singer Gwen Stefani). A number of young New Zealanders on their travels to Japan have encountered the Lolita in Harajuku and have become enamoured with the movement.

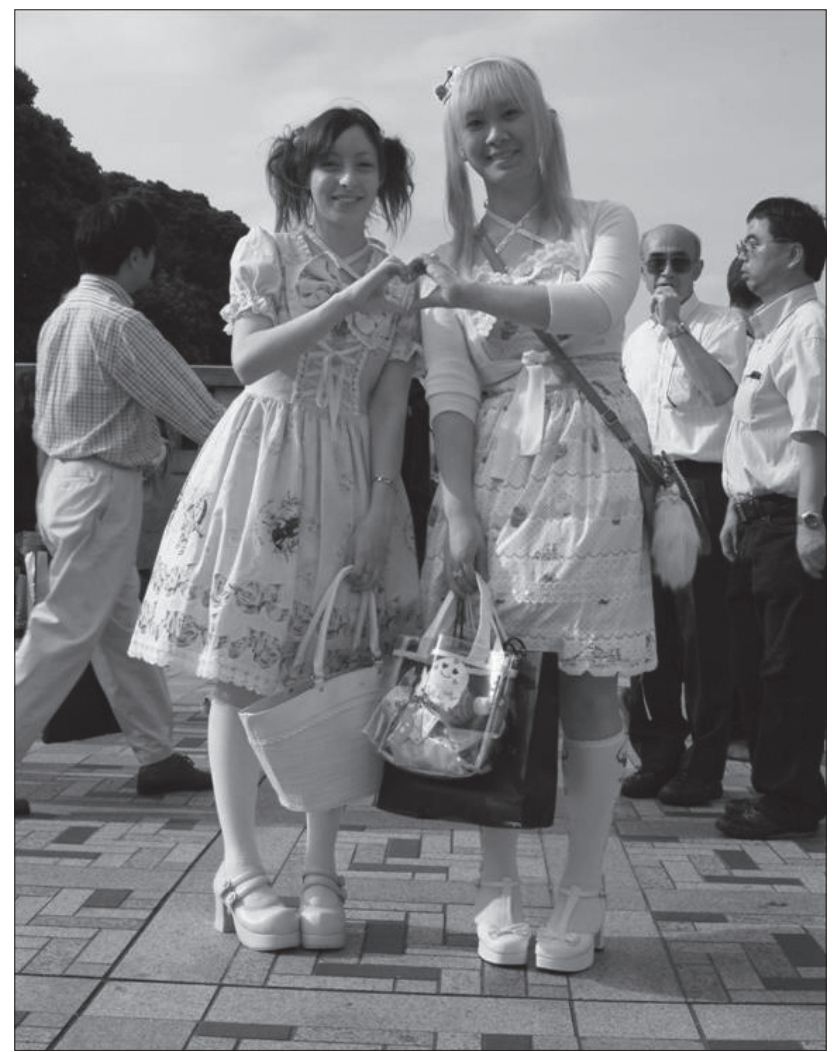

Figure 3: Anna Boissier and Chloe, on the Jingu-bashi, Harajuku Station Bridge, at the entrance to the Meiji-Jingu Shrine, Tokyo, 8 July 2007.

Photograph Bevan Chuang. 
From Hello Kitty to Pokémon, Japanese popular culture is increasingly occupying a high profile worldwide (Allen and Sakamoto 2006:2). Mudie (2008:138) writes: 'the culture of Japan continues to make its way into global consciousness' and Roland Kelts, in a new book titled Japanamerica, has touted 'the current fascination with Japanese culture $[a s]$... "a third wave of Japanophilia". ${ }^{12}$ Phillip Brophy, during a guest lecture at the Auckland War Memorial Museum (21 September 2007), commented that in the UsA this post-war Japanese invasion of kawaii-ness can be viewed as symbolic revenge for the atomic bomb, as millions of Americans spend a fortune on 'cute' Japanese merchandise.

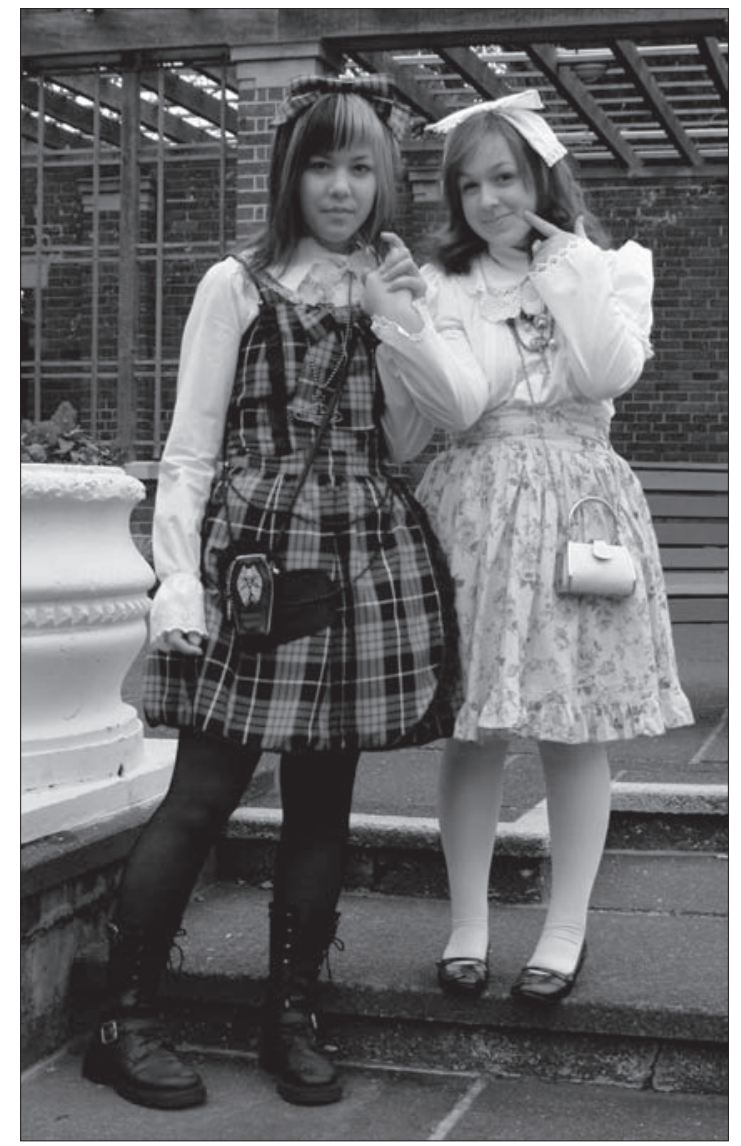

Figure 4: Bomi Park and Ashleigh Quayle, at the Wintergarden, Auckland Domain, 2007. Photograph Bevan Chuang. 
In New Zealand, this cultural saturation can be demonstrated by the popularity of the Armageddon Pulp Expo, an annual event, held in Auckland, Wellington and Christchurch, that seeks to attract fans of science fiction, pulp fiction, comics, animation, computer games and gaming consoles, of which much of the content of all categories is Japanese. A prominent sight at Armageddon is the 'cosplayer'. Related also to the Japanese Lolita movement is the notion of cosplay (kosupure = 'costume play/display'), the practice of dressing and parading as a favourite manga (Japanese still cartoon, illustration) or anime (Japanese moving-image illustration, animation) character (Figure 5), ${ }^{13}$

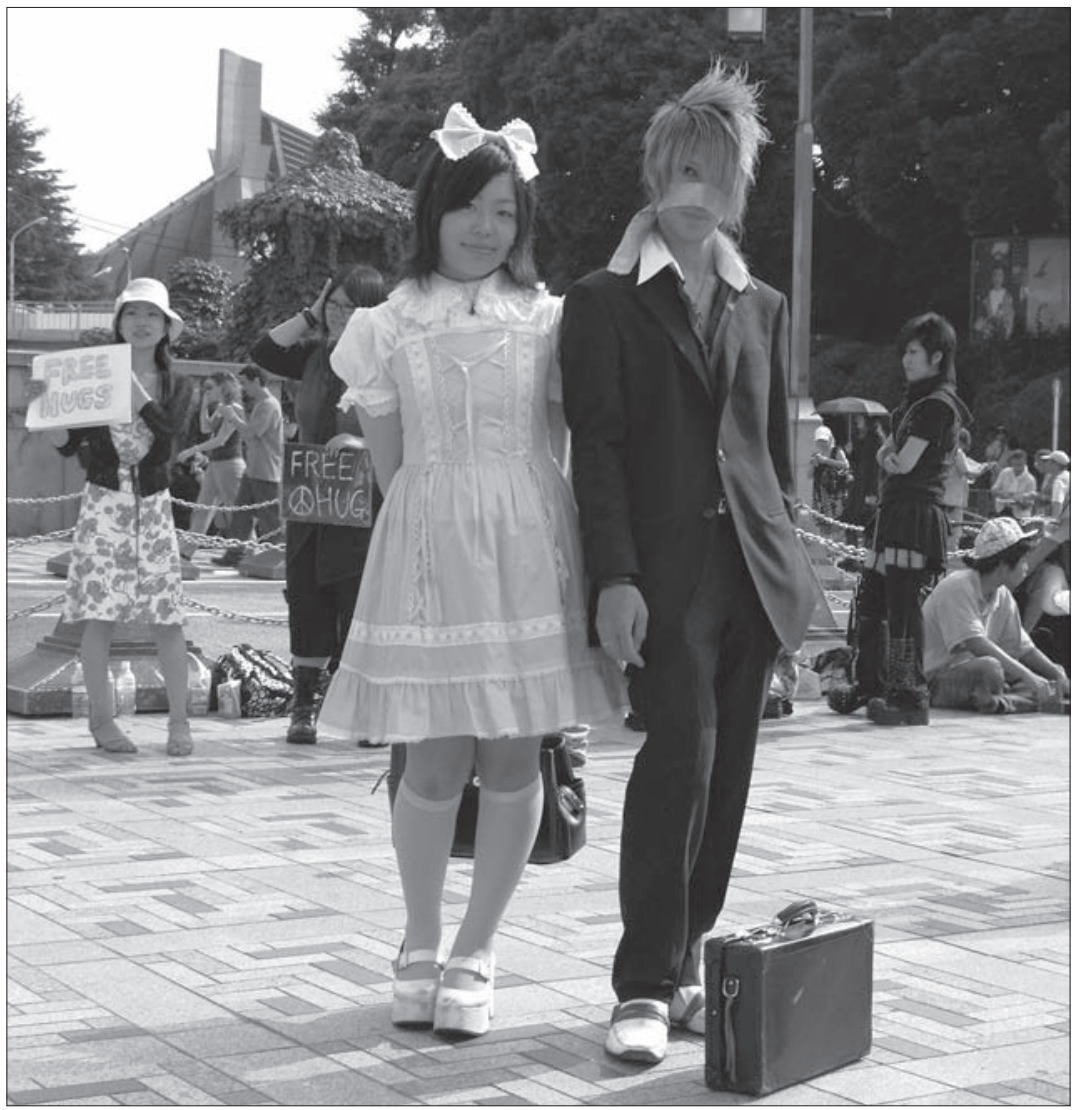

Figure 5: Kaina Kisaragi (Lolita) and Kanade Asakiri (Cosplayer), on the Jingu-bashi, Harajuku Station Bridge, at the entrance to the Meiji-Jingu Shrine, Tokyo, 8 July 2007. Photograph Bevan Chuang. 
which is rapidly gaining ground as an interest for young New Zealanders. At the Auckland venue in 2007, the Cosplay Awards was one of the most popular events, with cosplayers and spectators spilling out of the ASB Auditorium stalls at the Aotea Centre. Although figures from Western sci-fi films and comics were represented, the emphasis was on characters from Japanese animation. Mixed amongst the cosplayers, in both Wellington and Auckland, were also New Zealand Lolita.

As the acts of dressing up and street display are strong elements driving the Gothic and Lolita subculture, it is not surprising that the motivation towards cosplay often includes an attraction to the Japanese Lolita style. ${ }^{14}$ Mudie (2008:137) comments: 'the evolution of new trends in Japan [has] always been closely linked to what's going on in the streets.... This means popular culture, like manga and anime, long influenced the way people dress.... You see it most literally [with] cosplay'. The relationships between manga, anime, cosplay, street fashion and Gothic and Lolita are increased by the representation of the Lolita-type character in versions of shōjo (young girls') manga fiction (graphic novels) and anime, such as the Rozen Maiden series, Princess Ai, Kamikaze Girls, and Petite Cossette, all of which are available in New Zealand as printed literature or on DVD through major bookstore chains and online shops. Manga gothic novels, 'these distinctly Japanese forms of comics, [are]... flying off [New Zealand] shelves' (Mudie 2008:134).

There has been research into the popularity of manga in Auckland, particularly for Asian immigrants and international students, and the possible added meanings and values this suggests. It has been said that, for young Asian newcomers, this interest in manga is a continuation of previous habits and a provision of familiarity and security (Sunaoshi 2006: 99). ${ }^{15}$ Therefore, with the number of young Asians that form the majority of international students in New Zealand; the fascination of local youth with elements of Japanese popular culture; and connections between popular culture, such as manga and anime, with cosplay and the Gothic and Lolita subculture, the environment here is conducive to young people beginning to consume the Lolita style.

LOLI-POP - THE JOURNEY

One half of the world does not know how the other half lives

Godoy suggests: 'you could say the girls in the Goth-Loli scene are the female version of otaku' (Mudie 2008:137). According to Joseph Dela Peña (2006:3), otaku are members of 'a subculture born from the popular culture of post-war 
Japan'. Although the term 'otaku' carries with it many different layers of meaning, both literally (linguistically) and culturally 'most seem to agree' that otaku are 'exclusively' male, usually teenagers or young men, and fanatic enthusiasts of manga/anime-based Japanese culture and everything related to it (Dela Peña 2006:3), such as graphic novels, television shows, movies, videos/DVDs, computer games, personal accessories, and even figurines or dolls. The 'otaku deals very much with obsession, a "mania... for elements that belong to a fictitious world"' (Dela Peña 2006:3, citing Hirano 2005:60). ${ }^{16}$ The same applies to Lolita, who like 'the guys who hang out and read manga... are really immersed in a specific culture' (Mudie 2008:138, citing Godoy). Their interest in 'childish' things, including similar media, toys and dolls, can also be observed in terms of an escape from the real world. ${ }^{17}$

Sometimes, this rejection of reality can include the literal refusal by youth to conform to society's expectations and accept adult responsibilities. Dela Peña (2006:15), in an investigation into this situation with the otaku, has highlighted stress as a cause, stating that 'young Japanese men, in their late teens and early twenties, face a bevy of social pressures.' The tension created by an 'overwhelming' necessity to be academically and professionally successful has been exacerbated since the 1990s when Japan 'witnessed a multiple breakdown of political, economic and socio-political orders... [which] induced a visible shift in the mood of society, reflecting an end to the glorious age of Japanese economic success on the global stage' (Dela Peña 2006:15-16, citing Iida 2000:424).

These conditions have contributed to a growing number of Japanese youth categorised as NEET ('Not in Employment, Education or Training') (Kelts 2007: 12). The NEET in Japan are commonly between fifteen and thirty four years old, among whom more than 60 percent are aged above twenty-five (Nakamura 2004), with smaller numbers, either consciously refusing to work, seek work, or gain education that would increase their chances of obtaining work (as opposed to those in similar situations, where this condition may be largely circumstantial or imposed). Added to this problem, as Yuniya Kawamura has written, 'fathers are losing their jobs for the first time in their lives, ${ }^{18}$ and mothers who used to be full-time homemakers now have to look for parttime jobs to supplement their household income' (Kawamura 2007:343). 'A feeling of helplessness, disillusionment, alienation, uncertainty and anger has permeated throughout society, from adults to children' and 'children find no hope in future Japan' (Kawamura 2007:343). These so-called 'post-bubble' kids, who may also no longer want to work as 'salary men' (Nakamura 2004), office workers or OLs ('office ladies'), ${ }^{19}$ find it hard to achieve the extremely high standards of academic benchmarks (Dela Peña 2006:15) or are unable 
to procure suitable employment in the current economic environment. Their values are also different to those of their parents, in that 'traditional Japanese beliefs, such as selfless devotion to employers, respect for seniors and perseverance, are collapsing' (Kawamura 2007:343, citing Kazuo Ijiri 1990). All of this combines to contribute to a generation of young people that is increasingly removed, intentionally or not, from what is perceived as a 'normal' progression into adult life.

As part of the exhibition development, the curators of Loli-Pop visited Japan, assisted by the Asia New Zealand Foundation, Museums Aotearoa, and AUT University. The trip was essential for primary research, which included documenting the latest fashion trends in this shifting subculture. During their visit to the Shibuya, Harajuku, and Shinjuku districts, the heart of cutting-edge fashion, high-end retail, and the most common place to encounter Lolita, the curators talked with many Japanese (and some Western) members of the Gothic and Lolita movement (Figure 6) ${ }^{20}$ This enabled them to locate the Lolita subculture within a current context and to analyse the movement in

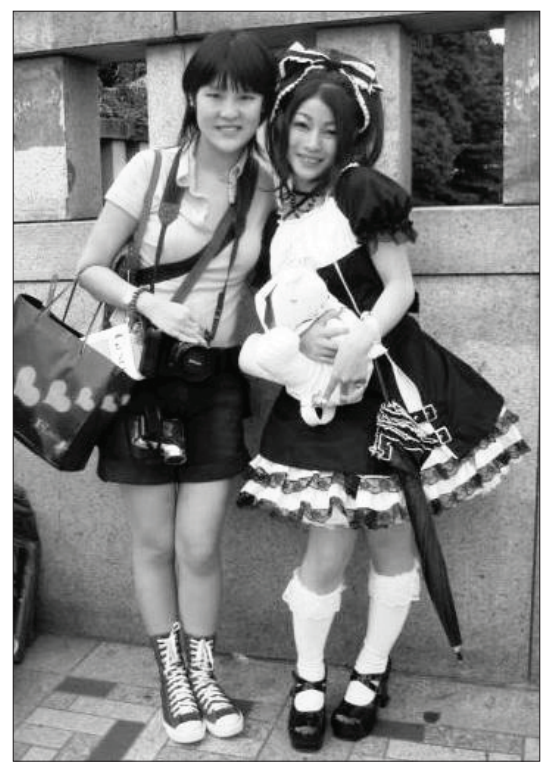

Figure 6: Bevan Chuang and Yuri, on the Jingu-bashi, Harajuku Station Bridge, at the entrance to the Meiji-Jingu Shrine, Tokyo, 8 July 2007.

Photograph Kathryn Hardy Bernal. 
association with contemporary socio-cultural understandings of Japanese youth and society. This Tokyo region is also where the curators witnessed an aspect of the NEET phenomenon. They observed many Lolita who appeared to have nothing much else to do but to meet up with friends and visit their favourite shops. ${ }^{21}$

The Lolita style originally shocked spectators, as it sat outside the normative of what was considered appropriate. ${ }^{22}$ Lolita was considered specifically as an act of rebellion against the family; dressing as a child was determined to be unacceptable behaviour because it symbolically, and sometimes literally, represented an apparent refusal to grow up, act one's age, and take responsibility. ${ }^{23}$ The curators were surprised, then, to observe a shifting attitude, represented by the large number of girls, many in school uniforms, and young women that were shopping for Lolita clothing with their mothers who were more than happy to treat their children to the most expensive higher-end brands, such as Baby the Stars Shine Bright (вTSSB), Metamorphose, and Angelic Pretty. ${ }^{24}$ This may be due to a changing status; once an underground movement, Lolita fashion has made the journey from the streets of Harajuku to designer recognition, with labels such as h.Naoto, by Naoto Hirooka, being shown at Tokyo Fashion Week 2008, and stores such as Mana's Moi-même-Moitié opening in Paris.

Many tourists flock to the Jingu-bashi, the bridge over Harajuku station at the entrance to the Meiji-Jingu Shrine, as this is often where Lolita meet up. It was mostly here that the curators photographed, filmed, and chatted with members of the Gothic and Lolita subculture for Loli-Pop. Participants in the Gothic and Lolita movement choose to wear fashions that are attention seeking, and gravitate towards areas, such as this Harajuku site, where they know they will be likely to be photographed by tourists. Most willingly pose for photographs for and with tourists. However, there lay a paradox in the behaviour of the 'Harajuku' girls and boys. When approached by the curators to be photographed for Auckland Museum, they were often either shy or rejected the proposition. It seemed that most did not mind that the tourists' photos could end up anywhere but, for some, giving signed permission for their images to be used was more daunting.

LOLI-POP - THE HURDLES

If you want peace, you must prepare for war

Despite the status of the Lolita subculture in Japan and a current Western fascination with all things Japanese, ${ }^{25}$ there were some ongoing difficulties in 
convincing all parties of the validity of the Loli-Pop exhibition at the Auckland Museum. From the earliest stages of the proposal, Loli-Pop encountered hurdles.

A key issue concerned the exhibition's title, as both 'Lolita' and 'Gothic' were considered controversial. 'Lolita' is loaded with sexually suggestive connotations, mainly due to a reputation that stems from a reading of Vladimir Nabokov's fictional character. 'Lolita' was deemed to be an inappropriate term by senior Museum staff. Email correspondence between the two curators containing 'Lolita' in the subject field and or message body was continually blocked as the 'system' recognised the word as offensive language. 'Gothic', too, invited its own stigma, in association with a certain interpretation of Gothic as related to 'Goth', and was frowned upon as unsuitable to represent Auckland Museum. Senior Museum staff decided that neither terms could be used in the exhibition's title, although they could be reproduced within the exhibition space.

The curators faced the dilemma of presenting an exhibition on the Japanese Gothic and Lolita movement when these words could not be used. They asked how this omission would attract a potential audience knowledgeable about this topic. Would a mere hint at the exhibition's subject matter be enough for people to realise that this was what the show was about? Would it even attract a new audience? The curators had sought to encourage an Asian and young audience. These are groups that are generally more aware of the cultural differences in the term 'Lolita. They are also sectors of the community that would likely be enticed by the words 'Gothic' and 'Lolita'.

At the first stages of development the curators proposed Lolita Style as the exhibition lead title, with a working subtitle of West meets East. A usual trajectory of this relationship is the 'discovery' of Japan in the nineteenth century, reproduced under the banner of 'East meets West', which implies an emphasis on Western invasion. The curators considered that this current episode of Japanophilia should be described as an inversion of the usual sensibility: 'West meets East' implies that Western society is introduced to the East; it reverts the notion of comparative power between East and West, and gives the East the conquering position where, in this case, 'Lolita style' is the victor. Museum staff bypassed this inference. The title was rejected because it was believed that audiences might expect an exhibition of traditional Japanese wares.

The challenge for the curators was how to refer to Gothic and Lolita without mentioning the discourse. It was thought that perhaps the Japanese phonetic 
form, gosurori (gothic-loli, goth-loli), might be a solution; the popular (if less correct) contraction, Loli-goth, eventually used continually throughout the exhibition text, would not suffice for the actual title, due to its emphasis on the 'goth' aspect. Through this process, however, Loli-goth became 'Loli-Pop', a pun that signifies the sweet style of the Lolita and wittily joins the term with the notion of popular culture. ${ }^{26}$

This was not the end to the troubles. Museum staff appeared to experience difficulties in understanding the exhibition topic and suitability for Auckland Museum. The show was marketed to become increasingly less about Japan and more about the movement's 'existence' in Auckland. As discussed, the subject matter was pertinent to the local audiences that the curators hoped to attract. A general ignorance about Gothic and Lolita, and a lack of comprehension about its worldwide currency and relevancy on the part of some staff members, caused a situation where a lack of faith, or mistrust, perhaps even panic, meant that the subculture's influence on the Auckland fashion industry became highly exaggerated by the marketing department.

The title that was agreed upon as a compromise between the curators and the supporting exhibition team was Loli-Pop: New Zealand perspectives on Japanese youth/street fashion. This gave less emphasis on a Japanese cultural invasion of the Western world and brought the topic closer to home. It was changed, without consulting the curators, to Loli-Pop: A downtown Auckland view on Japanese street fashion.

This change of title questions whether some museum staff are in touch with their audiences. The term 'downtown' is out-dated, reminiscent of the babyboomer Petula Clark generation, and seems hardly likely to bring fresher, younger audiences into places like museums, which are often viewed by young adults as mausoleums for obsolete things. Furthermore, the media alert, published on Auckland Museum's website and subsequently picked up on internet sites, stated that 'Asian popular culture and fashion has forever changed the look of downtown Auckland. Auckland Museum [sic] latest exhibition, LoliPop, explores one of the extreme edges of this culture: the Japanese Gothic Lolita phenomenon. ${ }^{27}$ During their research, the curators had identified three shops selling Gothic and Lolita items in Auckland: Smoove and Page in Little High Street, and Spacesuit on K' Road. Only one designer, Kath Bridges, was selling her Loli-influenced fashion under her label Kitty Bridges through Laundery. This was hardly an explosion that could change the face of anywhere, forever. 
This misleading information became more exaggerated when picked up by other media. It also became an emphasis for questioning when the curators were interviewed, creating some embarrassing moments. ${ }^{28}$ This twisting of the exhibition's purpose, however, appeared to appease those detractors at the Museum who refused or were unable to understand the merits and relevance of the original proposal.

There was a sense, because some senior staff did not know much about this topic or were unaware of the Japanese Gothic and Lolita movement, that some believed it lacked credibility. Instead Loli-Pop was a current, cutting-edge exhibition, backed up by motivations to improve relationships between the $\mathrm{Mu}$ seum and local communities, with the ability to educate new audiences. ${ }^{29}$

LOLI-POP - THE MEDIA

The opera isn't over until the fat lady sings

Despite misgivings in terms of the senior management and handling of the marketing side of the show, the Museum's publicity team was very supportive and, with its assistance, Loli-Pop generated much excitement and attracted unprecedented media attention for a small-scale temporary show at the institution. This resulted in many national and international articles and reviews, commercially published and online, in sources such as China Daily (one of the largest readerships in the world), China Economic Net, and The New Zealand Herald, as well as several television and radio segments. The curators were interviewed for World TV, Asia Downunder, The Asian Report with Suzanne Schockmann for Radio New Zealand, and by Nick D for Special Features, C4TV. This was the first time that a non-touring Auckland Museum exhibition had received worldwide attention.

LOLI-POP - THE FEEDBACK

Every cloud has a silver lining

Loli-Pop is reported to have attracted an audience of more than 500 per day for the two months it operated. Feedback from Front of House staff was very positive, with comments that visitors had asked specifically for the exhibition, highlighting they had known about Loli-Pop before arrival and had visited Auckland Museum for that purpose. One Front of House official commented that a young woman had returned to the till and paid an extra five-dollar 
donation; she apparently felt that the Museum deserved more as Loli-Pop had made her visit worthwhile.

According to staff, the exhibition attracted new types of visitors, such as Goth, Punk, and Emo (i.e. 'emotional' contemporary Goth/Punk) teenagers, and larger numbers of young Asians. Some wore Lolita fashions, including one girl who was carrying a doll dressed identically to herself. The exhibition was eye-opening and educational for staff, as well as audiences. ${ }^{30}$

LOLI-POP - UNSUBSTANTIATED FEAR

It is easier to pull down than to build up

The exhibition gained support from the Asia New Zealand Foundation, $\mathrm{Mu}$ seums Aotearoa, the Human Rights Commission, and AUT University, for the ability to promote understanding and engage with Asian and international student communities, and to forge relationships between these groups, AUT University and the Auckland Museum. Ironically, less faith was demonstrated by the Museum.

The project received praise and support mainly from non-technical staff, mostly with non-museological backgrounds. Some staff members with museological backgrounds were pessimistic about whether this would be a worthwhile exhibition. Many questions were raised about the justification for the curators' research travel to Japan. The exhibition itself, let alone the trip, was not considered relevant to the Museum or potentially the Collection. Unfortunately, the success of the exhibition did not change the view of some Museum staff.

Many staff did not believe that Loli-Pop would become an attractive exhibition, or that it showed any evidence of academic substance. It was viewed merely as an 'experiment' or 'filler.' The show was touted as serving the purpose of filling a hole in the Exhibitions schedule.

LOLI-POP - ACCOMPLISHMENT

\section{After a storm comes a calm}

The Loli-Pop exhibition enhanced not only the profiles of the curators and designers but also that of Auckland War Memorial Museum, especially for several of AUT University's Fashion students. Some, particularly those from overseas, visited the institution for the first time due to their involvement with 
or interest in the show. In some cases, Loli-Pop also positively affected some of the students' everyday lives, including their experiences at AUT, as well as, for international students, their memories of New Zealand.

It has been said that international students are less likely to engage with domestic students and members of host communities, tending to develop friendships with other co-national or international students (McGrath, Stock and Butcher 2007:11-12). In several instances, Asian students who participated in Loli-Pop 'came out of their shells' and 'blossomed' after being included as models, 'TV stars' and hosts. They began to mix with students outside their own cultural groups, to make new friends, and excel in their own creative endeavours; they became visible.

A Taiwanese domestic student, chosen as both a model and host, recalled the opening function: 'I had a lot of fun on the night and started to realise that my AUT life before [the exhibition] had gone totally wrong. I very much shut myself away from others and was worried [about not speaking] 'perfect' English. I do feel [like I] opened [up] after this experience, and I perceive the whole identity issue a bit differently'. This student was 'very excited' to be selected and said that Loli-Pop had raised an awareness and created an interest in the Gothic and Lolita movement, which had inspired that person's own design practice. One of the local 'Loli-girls', a secondary school student already influenced by the style, found that the exhibition helped her to decide to study a Bachelor of Design (Fashion) degree at AUT.

The young people who contributed to Loli-Pop, or participated in its opening night, became 'celebrities' of and ambassadors for the exhibition. Several were interviewed and or photographed by the media, helping to spread the word about the show to the New Zealand public. Many of the AUT students who attended the function designed and made Gothic or Lolita outfits for the evening and, together with Auckland 'Loli-girls', acted as exhibition guides and conversed with the crowd about their own creations.

Since the Loli-Pop exhibition, there is an increased awareness and acceptance of Japanese Gothic, Lolita and Punk culture in Auckland. These styles are becoming less alien to Aucklanders as more retailers stock genuine Asian brands of Gothic and Lolita clothing and a number of Lolita are being spotted around town. One boutique imported an increased shipment of the label GLP (Gothic Lolita + Punk) to coincide with the Loli-Pop opening, and was so successful that they continue to hold this level of merchandise at their inner-city store. 
IN CONCLUSION

There is no royal road to learning

In keeping with the criteria for the Asia New Zealand Museums Award, the Loli-Pop exhibition assisted the professional development of staff in areas of Asian expertise and developed effective links with Asian communities in New Zealand. It allowed the curators to acquire and improve their exhibition development skills and strategic planning techniques. It also provided an opportunity to empower staff in areas of Asian expertise to develop something tailored for the Asian communities in Auckland.

If museums and galleries around the world are serious about connecting with their local communities, they need to ensure that their staff members can represent the interests of racial minority groups in terms of management responsibilities, in order to provide long-term strategic goals that support a multicultural vision. The empowerment of ethnic minority staff can allow institutions to be better connected with their communities, and provide a more diverse insight into the decision making and programming process, as these employees are often more in touch with the best and most appropriate methods to communicate with their own cultural groups.

Although museums and galleries in New Zealand may have adopted the bicultural structure and implemented policies to improve and encourage the employment of Maori staff, and strategies to properly represent Maori communities, the time has come to look at the future for New Zealand as an increasingly culturally diverse nation and begin to adopt equitable schemes for advancing the situation for other ethnic groups. In dealing with this issue earnestly, institutions will be able to expand their engagement with all sectors of their local populations, and thus increase visitor numbers.

A programme that is well designed and created for the interests of the community will not only attract new visitors but will create a lasting impact. Institutions need to steer away from 'instructing' their visitors about what they desire or need to see in order to facilitate a positive learning experience for audiences. Museums and galleries will only be truly productive and successful if they can achieve relevance to multiple audiences. 


\section{ACKNOWLEDGEMENTS}

The authors would like to acknowledge Auckland War Memorial Museum, AUT University, Museums Aotearoa, the Asia New Zealand Foundation, and the Human Rights Commission, for their support in the development of the Loli-Pop exhibition. They would also like to thank Angie Finn, Lize Niemczyk, Yvonne Stewart, Gabriella Trussardi, and Carmel Donnelly for their contributions to the exhibition content; and to make a special mention of all the girls and boys they met in Tokyo; the five AUT Bachelor of Design (Fashion) student models, Emily Huang, Emily Wang, Shangshang Cookie Wang, Shiahug-wen (Sean) Kuo, and Yanling Wang; the Auckland 'Loli-girls' Ashleigh Quayle, Bomi Park, Zannii Anderson and Yuriko; and all the young people who dressed up to host the opening function, in support of our exhibition.

\section{NOTES}

1 'Asian' is defined by Statistics New Zealand as East Asian, South Asian, and South East Asian. This definition is used in this paper.

2 See Auckland War Memorial Act 1996, Section 11; The Museum of New Zealand Te Papa Tongarewa Act 1992, Section 8; Otago Museum Trust Board Act 1996, Section 3; and Canterbury Museum Trust Board Act 1993, Section 3.

3 This is also the case with many arts and cultural organisations in Auckland. At the 2008 New Zealand Diversity Forum (23-26 August), Helen Bartle spoke of Creative New Zealand's concern that, according to their 2006 survey, most Asians in this field are employed in low-status, administration, or volunteer occupations.

4 Proverbs are from Speake (2004).

5 'Lolita' is used as both the singular and plural form.

6 Kawaii = 'cute'; kawaisa $=$ 'cuteness'. According to Christine Locher, 'kawaii' is derived from the Japanese word, kawayushi, meaning 'shy' and 'embarrassed', and associated with being 'pathetic' and 'vulnerable', but also 'lovable' and 'small' (Locher 2002; Kinsella 1995). The characteristics of kawaii are now seen as anything childlike, adorable, and innocent (Locher 2002; Kinsella 1995). Kinsella has claimed that in Japan 'cuteness' reached a 'height of saccharine intensity' through its dissemination via mass media in the 1980 os (Locher 2002). 'Kawaiiness' has since permeated many aspects of Japanese culture, from food, toys, entertainment media (games, illustrated books, animation, etc.), fashion and 
personal grooming, to mannerisms (Garger 2007). It is also strongly associated with the 'cute' appearance and 'behaviour' of the Japanese Lolita. However, both the Goth-Loli movement and the concept of kawaii are much more complex phenomena, as are their relationships with each other, and can only be touched on in the context of this paper. For the psychology behind 'cuteness' in Japan see Kinsella 1995, Locher 2002, and Garger 2007.

7 Vladimir Nabokov released his novel, Lolita, in 1955. The name Lolita has been coloured by the protagonist of this story ever since, and has come to mean a promiscuous or sexually provocative young girl, or 'nymphet'.

8 Mana, currently with the group Moi Dix Mois, often takes on the persona of the Gothic Lolita both onstage and off. He is also a leading fashion designer of the Japanese Gothic and Lolita movement. With his two ranges, Elegant Gothic Lolita (EGA) and Elegant Gothic Aristocrat (EGA), for his label Moi-même-Moitié (with boutiques across Japan, and more recently Paris), he may have been one of the first, if not the first, to use the words 'Gothic' and 'Lolita' conjointly.

9 The dolls were from Kathryn Hardy Bernal's collection. Named Pullip (female), Namu (male) and Taeyang (male), these dolls are a collaboration between the Japanese toy company Jun Planning and Cheonsang Cheonha (Korea), and have been produced since 2003. Along with Blythe, a doll first manufactured in 1972 by Kenner (USA), and now Takara (Japan), Pullip (the collective name) is highly prized by Lolita.

10 All Aut University staff and students involved in Loli-Pop voluntarily gave their time and creative energies to the exhibition and Auckland War Memorial Museum.

11 It may be asked why the curators did not display authentic Japanese designed and produced Lolita garments and fashion accessories with the AUT lecturers' creations. This would have been preferable, and was the original intention and part of the reason for proposing the research trip to Tokyo. However, neither a budget was provided nor any funding obtained for this purpose.

12 The first wave was in the nineteenth century and is identified as the influence of Japanese art and design, particularly that of woodcut prints by artists including Hokusai and Andō Hiroshige, on Western artists such as Whistler, Manet, Monet, and Beardsley. This movement, known as Japonisme, was related to the Aesthetic Movement. This wave emerged during the 1860 s, after Colonel Perry had sailed his American fleet into Edo Bay in the 1850s, and coerced Ja- 
pan into negotiating trade agreements with the West, resulting in the so-called 'discovery' of Japanese artefacts, which penetrated the European market. The second wave, according to Kelts, was the poetry of the beatnik generation of the 1950s, inspired by haiku and zen philosophies, and the writings of Jack Kerouac (Mudie 2008:138). The third wave of so-called 'Japanophilia' that Kelts refers to is especially apparent in East and Southeast Asian countries (Iwabuchi 2002: 21; 2006:16). This cultural inundation of parts of Asia can be likened to the Americanisation of Japan since wWII, but is also representative of a symbolic shift in power from the USA to Japan (Iwabuchi 2006:20). Young people from places like Taiwan and Hong Kong perceive Japanese culture, rather than American, to be closer to their own and therefore more desirable.

13 In Japan and worldwide, cosplayers often copy the images of their favourite J-Rock (Japanese Rock) or Visual-Kei musicians, such as Malice Mizer's Mana. This has helped to fuel the popularity of the Gothic Lolita image as, since the 1990s, many followers of Mana have adopted his Lolita style.

14 According to Dela Peña (2006:27), it is common to see a large number of Lolita at anime conventions in the USA. His thesis discusses the connections between manga, anime, and cosplay.

15 This suggests that Japan's aggressive colonial past has not prevented the acceptance of Japanese popular culture in East and Southeast Asia by younger generations (Iwabuchi 2006:25). Historically, East and Southeast Asians, including those raised in New Zealand, have often been strongly opposed to anything Japanese.

16 Otaku are often interested in cosplay (Dela Peña 2006:12).

17 Otaku are sometimes considered to be socially withdrawn or disconnected from reality, because their obsession with watching TV and videos/DVDs, reading, and computer games often sees them isolated at home, inside their bedrooms. In extreme cases they only venture out to attend special meet ups or conventions (most material that interests them is available through the internet and online shopping). This is usually a temporary phase. Otaku should not be confused with hikikomori, whose behaviour has been defined as 'acute social withdrawal' (Dela Peña 2006:17-23). Hikikomori have been identified as seriously disconnected from reality; their self-imposed confinement has led, in many instances, to psychotic and violent episodes, including the committal of rape, assault, and murder, as a way of lashing out against the 'society from which [they find] no refuge' (Dela Peña 2006: 17-23). 
18 Kawamura (2007:345, n. 2) emphasised the seriousness of this: 'Japanese men have a strong belief in lifetime employment' and 'it used to be against their cultural norm to change jobs.'

19 Sometimes due to a fear of early death from overwork (karoshi), a common experience for previous generations.

20 Chuang speaks conversational Japanese. Hardy Bernal chatted to English speakers.

21 The curators were informed that Lolita would congregate in large numbers, doing little else except 'hanging out' with friends and shopping, only on weekends, as otherwise they were at school or work. Instead the curators encountered many Lolita on weekdays. The curators assumed these girls were past school age and not employed in full-time work.

22 Parker (2004) claimed that despite 'the nation's reputation as a culture with a love of all things cute, many in mainstream Japan are contemptuous of the Lolita look... [Fans] talk about being called stupid by strangers, getting mean looks, and having chewing gum stuck to their dresses.'

23 Like otaku, Lolita can totally immerse themselves in their lifestyle, which means that social responsibilities are sometimes ignored. However, the curators witnessed Lolita in retail employment, albeit at Lolita boutiques.

24 A full ensemble by a leading designer, including shoes and headwear, would currently cost a minimum of approximately NZ\$850.00.

25 See Ella Mudie (2008) for more on the contemporary Western interest in the 'Japanesque'.

26 The term 'loli-pop' is unfortunately tainted with a whole other set of problems, particularly related to pornography in Japan. To a Western audience this wording ironically suggests a notion of innocence.

27 This published media release also used, misused, and misquoted statements, notions, theories and previous research material belonging to Hardy Bernal. Failure to properly acknowledge this information means that other writers have continually used these ideas without knowing their original source, or attributing misleading comments to the wrong author. This compromised the originality 
of a thesis that was in process since 2002. When Museum staff were alerted of this, no compensation, substantive amendments or apologies were made.

28 Interviewers badgered the curators regarding where Lolita were congregating in Auckland. This also demonstrates no real understanding that Lolita-inspired clothing is a fashion style and not fancy dress.

29 If the curators had been given more support and a budget by the Museum, they would have been able to demonstrate their full vision for this event, and shown authentic Lolita objects from Japan, making this exercise groundbreaking and cutting edge. Fortunately the photographs of Japanese Lolita in Japan proved to create great interest.

30 The exhibition closure coincided with the promotion of the Darwin blockbuster exhibition, so there was no official opportunity to undertake summative research on whether Loli-Pop had achieved the objectives in the original proposal. A visitors' book was not available at the show either; thus there was no ability to carry out a conclusive review.

\section{REFERENCES}

Allen, M. and R. Sakamoto 2006 Popular Culture, Globalization and Japan, New York: Routledge.

Ang, I. 2005 'The Predicament of Diversity: Multiculturalism in Practice at the Art Museum', Ethnicities, 5(3):305-320.

Brophy, P. 2007 'Sexual Robots and Plastic Humans in Anime', paper presented at Auckland War Memorial Museum, Auckland, 21 September.

Dela Peña, J. L. 2006 'Otaku: Images and Identity in Flux’, East Asian Language and Civilization Honors Thesis, College of Arts and Sciences, University of Pennsylvania, CUREJ: College Undergraduate Research Electronic Journal, ScholarlyCommons@Penn,http://repository.upenn.edu/curej/9

Denniston, H. 2003 Holding up the Mirror: Addressing Cultural Diversity in London's Museums, London: Association for London Museums Agency.

Friesen, W. 2008 оUтLоок 06 - Diverse Auckland: The Face of New Zealand in the $21^{\text {st }}$ Century?, Wellington: Asia New Zealand Foundation. 
Garger, I. 2007 'Hello Kitty: One Nation Under Cute', Psychology Today, March/ April, 40 (2):32-33, http://www.psychologytoday.com/articles/pto-20070319ooooo4.html

Hardy Bernal, K. 2007 'Lolita in Japan: An Innocent Goth', MQ Museum Quarterly: The Quarterly Magazine of Auckland War Memorial Museum, Spring (112): 33 .

Heywood, F. 2006 'Museum Directors' Report Outlines Targets for Improving Staff Diversity', Museums Journal, 106 (6): 6.

Hirano, K. 2005 'Ani-mania: The Influence of Anime Artists is Not Just a Passing Fad Say Experts, and The Reason Lies at the heart of Japan's Artistic Culture', WWD (Women's Wear Daily), 31 March: 60.

Hirano, K. 2004 'Loli Goth Pop', wwD (Women's Wear Daily), Fashion, 21 October: $62 \mathrm{~S}$.

ICOM 2006 Code of Ethics for Museums, Paris: International Council of Museums.

Iida, Y. 2000 'Between the Technique of Living an Endless Routine and the Madness of Absolute Degree Zero, Positions (8): 423-464.

Ijiri K. 1990 'The Breakdown of the Japanese Work Ethic', Japan Echo, XVII (4):3540.

Iwabuchi, K. 2006 'Japanese Popular Culture and Postcolonial Desire for "Asia", in M. Allen and R. Sakamoto (eds) Popular Culture, Globalization and Japan, New York: Routledge: 15-35.

Iwabuchi, K. 2002 Recentering Globalization: Popular Culture and Japanese Transnationalism, Durham: Duke University Press.

Kageyama, Y. 2006 'Cute is King for the Youth of Japan, but it's Only Skin Deep', The New Zealand Herald, 16 June: в3.

Kawamura, Y. 2007 'Japanese Street Fashion: The Urge to be Seen and to be Heard', in L. Welters and A. Lillethun (eds) The Fashion Reader, Oxford and New York: Berg: 343-345. 
Kelts, R. 2007 'Future Tense', Metropolis, 6 July:12-15.

Kinsella S. 1995 'Cuties in Japan', in L. Skov and B. Moeran (eds) Women, Media and Consumption in Japan, London: Curzon Press: 220-254.

Lavine, S. D. and I. Karp 1991 'Introduction: Museums and Multiculturalism', in S. D. Lavine and I. Karp (eds) Exhibiting Cultures, Washington: Smithsonian Institution Press: 1-9.

Locher, C. 2002 'The Cult of Cuteness in Japanese Youth Culture', Scholarly Paper, Kyushu-University, Fukuoka, Grin Publishing http://www.grin.com/ebook/14118/the-cult-of-cuteness-in-japanese-youth-culture

McGrath, T., P. Stock and A. Butcher 2007 Outlook 05 - Friends and Allies: The Impacts of Returning Asian Students on New Zealand-Asia Relationships, Wellington: Asia New Zealand Foundation.

Mudie, E. 2008 'Turning Japanese: Manga Makeover', Pulp, Winter (58):132-139.

Nakamura, A. 2004 'No Education, No Employment, No Training: Being NEET Not so Neat for Nation's Youth', Japan Times, 19 June, The Japan Times Online http://search.japantimes.co.jp/print/news/nno6-2004/nn20040619f2.htm

Nishime, L. 2004/2005 'Communities on Display: Museums and the Creation of the (Asian) American Citizen', Amerasia Journal, 30 (3): 40-60.

Parker, G. 2004 'Parasols and Pink Lace: Japan's Lolita Girls; “I'd Like to go Back in Time, Like to the Era of Marie Antoinette", says 24-year-old Nurse', Globe Style, The Globe and Mail, 25 September, in Factiva, unsw Library Databases.

Porter, G. 2004 Diversify! The Impact of Positive Action Traineeship, London: MLA (Museums, Libraries and Archives Council).

Shaw, L. 2004 Changing the Culture of Museums and Galleries: Creating a More Diverse Workforce, London: Museums Association.

Speake. J. (ed.) 2004 The Oxford Dictionary of Proverbs, Oxford: Oxford University Press, Oxford Reference Online, Aut University Electronic Resources. 
Statistics New Zealand 2008 National Ethnic Population Projections 2006 (base) 2026 Update Information Release Wellington: Statistics New Zealand.

Statistics New Zealand 20062006 Census of Population and Dwellings, Wellington: Statistics New Zealand

Steel, P. 2006 'MA Poll Finds Regional Museums Lack Diversity', Museums Journal, $106(7): 11$.

Stephens, S. 2006 'Diversity Work Placement Scheme Could be Rolled Out', Museums Journal, $106(1): 13$.

Sunaoshi, Y. 2006 'Who Reads Comics? Manga Readership Among First Generation Asian Immigrants in New Zealand', in M. Allen and R. Sakamoto (eds) Popular Culture, Globalization and Japan, New York: Routledge: 94-114.

Wajid, S. 2008 'Becoming a Museum Trustee Seems Like a Good Way for Minorities to Shape Policies, So Why are the Opportunities Available Not Put to Better Use?', Museums Journal, 108 (2):16

Weil, S.E. 2002 Making Museums Matter, Washington: Smithsonian Institution Press.

Yoshitomi, G.D.J. 2002 Engage Now! An Arts Worker's Guide to Deepening Experience and Strengthening Participation in the Arts, Pennsylvania: Heinz Endowment. 